\title{
The relationship between perceived coaching behaviours and team cohesion among Malaysian National Junior Athletes
}

\begin{abstract}
Based on Carron's (1982) model of cohesion, this study examined the relationship between perceived coaching behaviours and group cohesion in interacting sports teams among national junior athletes in Malaysia. The subjects, which were comprised of 150 athletes, were asked to respond to survey questions based on the Leadership Scale for Sports (LSS) and the Group Environment Questionnaire (GEQ). The results suggest a significant relationship between coaching behaviours and team cohesion. Coaches who were perceived as engaging in democratic behaviours, higher levels of training and instruction, social support and positive feedback, tend to have athletes with higher levels of task and social cohesion within their teams.
\end{abstract}

Keyword: oaching Behaviours, Team Cohesion, Social Cohesion 